\title{
Naiive Designers' Information Use during the Design Process in a Low-Resource Classroom
}

\author{
Nicolaas Blom ${ }^{1 *}$, Grietjie Haupt ${ }^{1}$, William Fraser ${ }^{1}$ \\ ${ }^{1}$ Department of Science, Mathematics and Technology Education, University of Pretoria, SOUTH AFRICA
}

Received 16 January 2018 - Revised 19 March 2018 - Accepted 9 April 2018

\begin{abstract}
Facilitating the design process in low-resource Technology classrooms has become increasingly challenging in the 21 st century. This research focuses on the types of information sources used during learners' design processes. We examine the information sources that nine South African Grade 9 learners from a low-resource school used while they were engaged in a mechanical systems and control design task. They worked in groups of three to design a machine to lift logs from the ground onto a truck. We utilised a Think Aloud Protocol Study to collect concurrent verbal, visual and temporal data. The results indicate that Grade 9 design teams were predominantly engaged in problem solving activities by using mostly external sources of information during the early phases of the design process. If designing is the backbone methodology of Technology education, attention should be given to the information sources that learners use during designing.
\end{abstract}

Keywords: cognitive phases, design cognition, information sources, low-resource classrooms, technology education

\section{INTRODUCTION}

During the early phases of the design process, learners have to engage in an iterative process of structuring and solving their design problem (Dym, Little \& Orwin, 2014; Hay, 2017). The early phases of the design process are particularly challenging phases as this is when learners' level of uncertainty about how to proceed with their design process is higher (Jonassen, 2011). It is often difficult for learners to identify and define their design problem and to specify which directions to follow, due to the ill-structured nature of the design problems they deal with (Goel, 2014; Reed, 2016; Simon, 1973). Uncertainty is challenging for secondary school learners, who are considered to be untrained in focusing their attention (Gonçalves, Cardoso \& Badke-Schaub, 2016; Pieper, 2013) and thus struggle to choose which direction to follow. To reduce their uncertainty, learners search for internal and external information with the aim of structuring and solving the design problem they are faced with (Song et al., 2016).

Although teachers provide learners with some information related to their design problems, it would be impossible for teachers to explore all possible aspects of each learner's design problem beforehand due to time constraints (Mettas \& Norman, 2011). Furthermore, information given by teachers might be biased, i.e. have preferences toward specific solutions paths, which implies the prescribing of learners' design processes, which could potentially limit their creativity (McLellan \& Nicholl, 2011). Recent studies in South Africa (Kola, 2017; Mathumbu, Rauscher \& Braun, 2014) have also proven that technology teachers do not support the systematic development of learners' design processes, and provide limited facilitation of the cognitive processes during designing.

In light of the limitations of teacher-prepared information resources, other information sources including internet access, reference books and catalogues may help learners to structure and solve their design problems (Pieper, 2013). However, in South Africa, most classrooms and communities do not have sufficient information access. Of approximately 23471 public schools in South Africa (DBE, 2018):

- 18019 (70\%) do not have stocked libraries; and

(C) 2018 by the authors; licensee Modestum Ltd., UK. This article is an open access article distributed under the terms and conditions of the Creative Commons Attribution License (http://creativecommons.org/licenses/by/4.0/).

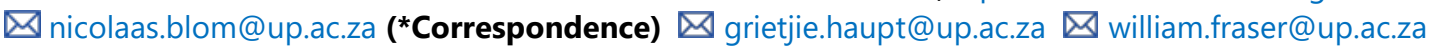




\section{Contribution of this paper to the literature}

- This paper suggests Extended Information Processing Theory (Haupt, 2018) as a novel theoretical framework through which secondary school learners' design cognition could be conceptualised.

- Current and future Technology teachers might improve their design process facilitation if they are aware of the relationship between learners' cognitive phases and available information sources during those phases.

- $15896(59 \%)$ do not have a computer centre.

The above-mentioned statistics imply that in the majority of Technology classrooms in South Africa, information is not easily accessible. It was our interest to conduct research in a low resource classroom, to investigate what types of information sources learners typically use during a mechanical systems and design task. For this study, we considered a low resource Technology classroom as a classroom that did not comply with the minimum resource requirements stipulated in the Technology Curriculum and Assessment Policy Statement (CAPS) (DBE, 2011). In Table 1, a list of requirements for Technology is provided, with which the case study did not comply.

Table 1. Resource requirements for Technology

\begin{tabular}{|c|c|c|}
\hline 1. Each learner must have an appropriate textbook & $\mathrm{x}$ & $\begin{array}{l}\text { In our case study, the school did not provide learners with an } \\
\text { appropriate textbook. Instead, only the teacher had a } \\
\text { textbook. }\end{array}$ \\
\hline 2. Each learner must have a 72-page A4 workbook & $\sqrt{ }$ & Each learner had their own workbook. \\
\hline $\begin{array}{l}\text { 3.Stationary including basic drawing instruments: pencil, } \\
\text { eraser, ruler and set squares }\end{array}$ & $x$ & $\begin{array}{l}\text { The participants only had access to basic stationery items. } \\
\text { However, they did not have access to drawing instruments such } \\
\text { as set squares, and protractors. }\end{array}$ \\
\hline 4. A designated teaching venue with a Technology teacher & $\sqrt{ }$ & $\begin{array}{l}\text { The school in which this study was conducted had their own } \\
\text { Technology classroom. }\end{array}$ \\
\hline $\begin{array}{l}\text { 5. Technology rooms must be secure, with doors that lock, } \\
\text { and with burglar-proofing if possible. Enough cupboards } \\
\text { should be available to store and lock away all resources }\end{array}$ & $x$ & $\begin{array}{l}\text { Although Technology classrooms were secured with a door and } \\
\text { lock, the classrooms did not have any storing space or lockable } \\
\text { cupboards available for storing tools, materials and projects. }\end{array}$ \\
\hline $\begin{array}{l}\text { 6. It is the responsibility of the school to provide each } \\
\text { learner with the minimum tools and material to meet the } \\
\text { needs of the subject }\end{array}$ & $\mathrm{x}$ & $\begin{array}{l}\text { The school did not provide learners with any tools or materials } \\
\text { for their projects. Learners had to source their own materials. }\end{array}$ \\
\hline
\end{tabular}

In addition, the school was located in a low-socioeconomic area as indicated by the monthly income of households, unemployment rates and food insecurity, as found by Abbey (2008) and Naidoo (2011) regarding the area in which the research site was situated.

Despite the prescriptions in the Technology curriculum (DBE, 2011) to develop all South African learners' investigation skills in finding, analysing and synthesising information, few pedagogical guidelines exist to guide Technology teachers' facilitation of the early phases in low-resource classrooms. A majority of technology and engineering curricula stop short of providing teachers with any details related to learners' efforts to search for and use information (Pieper, 2013).

For this paper, we aimed to use an extended information processing framework through which we could identify the information sources that secondary school learners use during the early phases of the design process. Examining the information sources that learners search for is important for practical and theoretical reasons. First, this knowledge can assist curriculum developers to develop much-needed pedagogical guidelines to ensure that teachers are able to facilitate the early phases of the design process. Second, this knowledge might help curriculum developers and teachers to design learning environments that are conducive to complex thinking that mirrors that of expert designers (De Vries, 2016; Haupt, 2015; Oxman, 2001). Third, viewing the design cognition of secondary learners through extended information processing contributes to the limited theories of cognition specific to Technology education (Grubbs \& Strimel, 2016; Petrina, 2010).

This investigation attempted to shed some light on what information learners searched for, which has implications for secondary Technology education, especially in low-resource contexts. Subsequently, this paper aims to address the following research question: What are the information sources that Grade 9 learners use during the early phases of the design process? Addressing this research question may help to guide teachers' decisions regarding the appropriateness of using information during learners' design tasks. It might also be beneficial to identify what information sources learners did not typically use in low-resource environments in order to design appropriate pedagogical interventions. 


\section{LITERATURE REVIEW}

\section{Designing as Problem Solving}

The distinction between well-structured and ill-structured problems has been well documented in the problem solving literature (Csapó \& Funke, 2017; Reed, 2016; Robertson, 2017), and has gained wide acceptance among researchers of design cognition. Designing as a cognitive activity is seen as a prime example of ill-structured problem solving (Goldschmidt \& Rodgers, 2013; Grubbs \& Strimel, 2016; Jonassen, 2011). Since the late 1960s, there have been many developments in understanding how designers solve ill-structured problems. The original work of Herbert Simon on ill-structured problem solving remains the dominant theoretical framework through which designing is conceptualised. Simon's work and its applicability to designing have also received many critiques. Subsequently, some of the of the original statements in Simon's work that deal with designing have since been qualified and refined (Dorst \& Cross, 2001; Gero, 1998; Visser, 2009).

In his problem-solving approach to design, Simon (1973) distinguishes two cognitive phases in design problem solving, namely, problem structuring and problem solving. Problem structuring refers to the psychological process of forming a mental, subjective representation that reflects the perceived problem state and desired outcome (Simon, 1973). Typical activities in the design process related to problem structuring include defining the problem to be solved by understanding the users' needs and the design context; proposing and modifying design requirements, limitations and constraints; and formulating design goals and sub-goals (Björklund, 2013; Dym et al., 2014). Problem solving refers to the psychological process of 'searching' for possible solutions in a design problem solving space (Simon, 1973). Typical activities in the design process related to problem solving include proposing alternative design ideas, elaborating on possible design ideas, and choosing design ideas that could be further developed and detailed into a final design specification (Dym et al., 2014; Goel, 2014).

Goel (1995) further characterised designing as involving four cognitive phases: problem structuring, preliminary design, refinement, and detail specification. This paper is only concerned with the first two cognitive phases, which constitute the early phases of the design process. In our experience, Technology teachers are still uncomfortable with the uncertainties of the problem structuring and preliminary solving phases, and prefer to give learners a well-defined design brief (Mettas \& Norman, 2011). Although a well-defined design brief might be beneficial for teachers for the purpose of managing learners' design processes, learners might be unaware of the need to structure their own design problem or consider the design context, which might prevent them from seeing their design project holistically.

Although the majority of professional design cognition studies have focused on the early phases of the design process (Dinar et al., 2015), several scholars maintain that the nature of the cognitive processes of professional and novice designers involved in the early phases remains unclear (Dorst \& Cross, 2001; Jin \& Benami, 2010; Kim \& Ryu, 2014). When design issues in general are brought home to the specificity of their application in Technology education, it becomes clear that there are few studies that have empirically investigated the cognitive nature of Technology learners' design processes at both theoretical and empirical levels (Strimel \& Grubbs, 2017; Wells et al., 2016). Recent findings in the literature focusing on the early phases reveal that the behaviours of Technology learners often differ from those of experts in key areas such as problem structuring, depth and breadth of the information sought, and time spent during individual cognitive phases (Atman et al., 2007; Kelley, Capobianco, \& Kaluf, 2015; Mohedas, Daly, \& Sienko, 2015). However, these studies have not yet explored what information sources naïve designers in secondary schools typically use during the early phases of the design processes. This paper speaks to this gap.

In their exposition of levels of design expertise, Lawson and Dorst (2009) have proposed that naive designers should be considered as the first level of design expertise. According to them, designing can also be done by ordinary people, who have not yet engaged in formal design training. They characterise naïve design processes as a mimicry of existing solutions where naïve designers make their design choices based on limited previous knowledge and design experiences (Lawson \& Dorst, 2009). Understanding how naïve designers engage in designing seems important because it marks the start of the process of developing design expertise. As such, this study focussed on the information sources used by naïve designers in a Technology classroom.

\section{Information Access and Use}

For this paper, we viewed an information source as any fragment of information that has been interpreted by the designer and prompts a reaction to explore the problem or solution space (Cash \& Gonçalves, 2017). In line with Extended Information Processing Theory, we could distinguish between two main types of information sources, including internal and external information sources. Internal sources include information that is located in the design task, for example, design requirements, constraints, limitations and intentions, or, stored in learners' 
memory. External information sources are located externally in the Technology learning environment and include sources such as drawings, textbooks, 3D modelling materials, and pictorial information.

Currently, a limited amount of literature empirically shows how designers, in general and specific to Technology education, use information sources (Gonçalves et al., 2016; Mohedas et al., 2015; Restrepo, 2006). It is for this reason that we reviewed literature from design cognition in general, and specific to Technology education. In general, a design team's need to gather information during the early phases of the design process is fundamental to creating successful design solutions (Bursic \& Atman, 1997; Cash \& Gonçalves, 2017; Mohedas et al., 2015). Dym et al. (2014) suggest that information gathering is an essential process during the early phases of the design process. In design practice, information sources typically include literature on modern solutions, experts, design codes and regulations; competitive products; heuristics; models; handbooks; local laws and regulations; suppliers' component specifications; prior experiences; and feedback from clients. Designers use these information sources to structure and solve their design problems.

Professional designers spend a considerable amount of time gathering information during designing (Gonçalves, Cardoso \& Badke-Schaub, 2014; Mohedas et al., 2015). During the design process, their need for several internal and external information sources changes over the course of their design task (Gonçalves et al., 2016). Designers typically search for different information sources to support their problem structuring efforts (Heisig, Caldwell, Grebici, \& Clarkson, 2010), and their idea generation and development phases; (Gonçalves, Cardoso, \& Badke-Schaub, 2013). Previous research has noted the value of information sources during the early phases of the design process, in particular, the positive effects of external information sources on idea generation (Gonçalves et al., 2016; Stables, 2010; Wu \& Wang, 2015). In addition, research findings have also shown how information sources can deter designers from exploring other solutions as they become fixated (Dinar et al., 2015; McLellan \& Nicholl, 2011; Nicholl \& Mclellan, 2005). Thus, information sources seem to have a substantial impact on designing, and are key to the exploration of the early phases of the design process (Cash \& Gonçalves, 2017).

However, very few studies have zoomed in on how designers use information sources during problem structuring (Mohedas et al., 2015; Summers, Joshi, \& Morkos, 2014), especially in secondary school technology classrooms (Pieper, 2013). Although some scholars are able to identify the cognitive phases involved during Technology learners' design processes (Kelley et al., 2015; Wells et al., 2016), they do not elaborate on the information sources that learners use during these cognitive phases. Gonçalves et al. (2016) suggests that the use of information sources during design activities supports the transition between problem structuring and problem solving. However, it is currently difficult to describe how information sources are influential during designing (Gonçalves et al., 2014), or how design situations build up from these information sources (Cash, Hicks, \& Culley, 2015). One reason for this limitation might be as a result of the research methodology that researchers are utilising, namely, Think Aloud Protocol Studies (TAPS). A majority of the studies on learners' design cognition using TAPS methodology do not gather data revealing what external information sources learners use during designing. Ericsson and Simon (1993) attribute this limitation to the 'near' unmanageability of the large amounts of data that may be accumulated as a result. As such, the objective of this paper was to provide some evidence of what information Grade 9 learners typically accessed and used during the early phases of their design processes.

\section{THEORETICAL FRAMEWORK}

This paper provides an alternative view of conventional Information Processing Theory that is currently emerging in the literature, namely extended information processing (Haupt, 2018). The Information Processing Theory of design problem solving has led to the belief that problem solving behaviour is dependent on a centralised internal processor of information localised in an individual designers' mind (Goel, 2014; Newell \& Simon, 1972; Ullman, Dietterich \& Stauffer, 1988). In this view, what learners think and what they do are seen as two separate activities. Furthermore, according to Information Processing Theories, the location of information solely resides in learners' memory, and therefore neglects to account for the role of the physical and social environment during the early phases of the design process.

In contrast to information processing theories, extended information processing recognises that designers' design task environment encompasses internal and external sources of information, irrespective of domain or level of expertise. Extended information processing theory developed as a subset of Situated Cognition (Robbins \& Aydede, 2009) and Distributed cognition theories (Hutchins, 2014). Extended information processing draws from the Extended Mind (Clark, 2006, 2008; Clark \& Chalmers, 1998), that reject exclusive internalist and externalist theories of cognition, in favour of an integrated model of cognition (Menary, 2007, 2010)

For the purpose of this study, an integrated model of design cognition was adopted. The authors furthermore believe that the design process is an integrated, continuous process in which designers, using internal and external information, develop a fit-for-purpose solution. 
The benefit of using an extended information processing framework lies in the descriptive power it provides in describing the development of learners' design activity in conjunction with the information sources that learners use during problem structuring and solving. Cash and Gonçalves (2017) emphasise that there are limited theoretical frameworks describing the development of design methodology in conjunction with information sources. As such, an extended information processing framework provides a means to study how Technology learners use information sources during the early phases of the design process.

\section{METHODOLOGY}

For this study, a pragmatic stance was adopted based on the integration of post-positivist and constructivist theories of design cognition (Petrina, Feng, \& Kim, 2008). In order to identify what information sources the learners used, we followed a concurrent mixed methods approach (Creswell, 2014; Teddlie \& Tashakkori, 2009) in which we utilised a case study research design (Yin, 2014). In order to collect data, we employed a Think Aloud Protocol Study (TAPS) methodology to study learners' design activities. Conducting a TAPS with the groups of participants allowed us to microscopically study when in the design process information sources were used. The authors studied three cases consisting of one group of two, and two groups of three Grade 9 Technology participants. The reason for using groups of participants rather than individual participants was based on maximising the verbal fluency among the participants during their TAPS. Welch \& Lim (2000) also recommends studying groups of participants instead of individuals in order to create an environment that is conducive to thinking out loud.

\section{Context of the Study}

The target population for this study comprised one high school Technology classroom situated in a low socioeconomic public school. We gained access to the research site via a teacher who was known to us, since she had been a Technology student of ours, approximately nine years ago. The Grade 9 participants were selected purposefully on the basis of their involvement with Technology for approximately 3 years. We confirmed with the Technology teacher that the members of the target population had already been exposed to at least six different design projects throughout their school careers. The Technology teacher also informed us that the target population possessed the necessary design skills to complete their design tasks, including investigating, designing, making, evaluating, and communicating skills (DBE, 2011), as well as conceptual knowledge about mechanical systems and control (DBE, 2011).

Prior to participating in this study, the target group completed their Term 2 work, focusing on the mechanical systems and control content area. The term was sequenced over eight weeks, comprising 20 contact lessons. During the lessons in weeks 1-4, the target group was engaged in enabling tasks, which introduced them to a range of mechanical systems and control concepts, building on their Grade 8 work. These mechanical systems and control concepts included the following conceptual knowledge (DBE, 2011, p. 53):

- Hydraulic/pneumatic systems that use restrictors, one-way valves: hydraulic press/jack;

- Gear systems - spur, bevel, rack and pinion, worm;

- Mechanical control mechanisms - ratchet and pawl; cleats; bicycle brakes; disc brakes;

- Belt-drive systems with more than one stage;

- Pulley systems - fixed pulley, moveable pulley, and multiple pulleys (block and tackle); and

- Systems where mechanical, electrical or pneumatic systems are combined.

The teacher taught these concepts to the target group mainly from a textbook (Clitheroe et al., 2013) while they completed enabling tasks. During weeks 5-8, the target group completed a Practical Assessment Task (PAT) in groups of four with the aim of designing and making a 3D model of a hydraulic water pump, drawing on their prior knowledge of integrated mechanical systems and previous design skills. No tools and materials were provided by the school for the target group to make their 3D models of the water pump; the learners therefore had to source their own 'affordable and easily accessible' materials.

The participants from the target group had also been exposed to several external information sources during their previous design projects. These external sources included: a workbook; Learning and Teaching Support Material (LTSM) such as worksheets, experiments and posters on the walls of the class and case studies. It should, however, be noted that the target population for this study did not have their own textbooks. Only the teacher had a Technology textbook, which was used to guide teaching and learning. The teacher copied important information for the learners and summarised the textbook. This was then given to the learners to paste in their workbooks. 


\section{Sampling}

For this study, we relied on convenience sampling to select one participating school, based on their geographical proximity in Gauteng, Pretoria and their availability to participate. We also used purposive sampling to select eight participants (three groups of learners from different Grade 9 classes). At our request, the teacher from the secondary school selected nine, verbally fluent candidates, of which one declined to participate at the last minute. In South Africa, where there are 11 official languages, but high school education is entirely conducted in English, fluency in English was a serious consideration to ensure the depth and richness of data. Such fluency often coincides with a high achievement in the demographics of secondary schooling (Trudell, 2007). Coincidentally, the sampling based on this criterion yielded nine female participants. Further sampling criteria that the authors gave to the teacher for participant selection included, the ability to work together as a group, and above-average design capability. The authors derived these criteria from the CAPS document for Technology as examples of exemplary design capability behaviour (DBE, 2011, p. 44). All the participants signed informed assent forms in line with the ethical clearance protocols of our institution. They had also been informed that they were at liberty to withdraw from the recordings at any time.

\section{Data Collection Strategies}

We interviewed the teacher to access information regarding the work already covered, after which we collected data during the course of two consecutive afternoons. We used a Think Aloud Protocol Study (TAPS) to collect evidence of the participants' use of internal and external information sources (Ericsson \& Simon, 1993). As such, we were able to concurrently collect a verbal protocol of the participants' utterances; and visual evidence of the participants' external representations, i.e. sketches, writings, 3D modelling, and temporal data of the participants' design task performance. The TAPS method requires the participants of a study to talk out loud as they are performing a given task while being video recorded (Ericsson \& Simon, 1993; Kelley et al., 2015)

The authors were able to elicit the design cognition behaviour of each group of participants by providing them with a design task (see Appendix A) that we adapted from a prescribed textbook suggested by the DBE (Johnstone et al., 2013). The authors adapted the design task on the basis of the participants' work from the previous term, focusing on concepts of mechanical systems and control. The participants did not have access to this design task prior to the study. In the given design task, the groups of participants were required to design a model of a lifting machine that could pick up logs from the ground and transfer them onto a transport truck. The participants were also instructed before the study to bring their workbooks to class, which contained their previous term's work. This had the potential to stimulate idea generation and enhance their access to external information sources.

The design task played a central role in eliciting the participants' information access and use during their design processes. We collected and analysed primarily qualitative data, which included concurrent verbal and visual data. The verbal data was collected sequentially from the start of the participants' protocols, while the visual data consisted of external representations that the participants produced in the form of sketches, 3D models and writings. Quantitative data was collected in the form of temporal instances of information access and use behaviour.

\section{Data Analysis}

The primary unit of analysis for this study was the verbal utterances made by the participants, which were clustered into modules that we could interpret as cognitive actions. A module was defined as "a complete portion of text uttered by a participant, without interruption from the other participants" (Welch, 1999, p. 24).

The data analysis and interpretation was guided by a multi-phase coding scheme derived from Ullman et al. (1988) and (Goel, 1995) that we applied to all modules. The result of this process was a microscopic analysis of the design process of each group of participants, which revealed when and where information sources were used during the early phases of the design process. The protocol analysis allowed the researchers to identify instances where the participants were engaged in problem structuring and problem solving. Furthermore, the researchers were also able to identify instances in which the participants used internal and external information sources.

\section{Quality Measures}

In order to ensure the consistency and repeatability of the coding procedures, the researchers utilised an intercoder reliability technique. Two researchers who were researching the early phases of the design process with similar coding schemes independently classified ten sample groups of verbal utterances according to the coding scheme for this study. The consistency of the agreement between the two researchers was determined by using the following formula: 


$$
\text { Inter }- \text { rater reliability }=\frac{\text { Number of agreements }}{\text { Number of possible agreements }} \times 100=\frac{9}{10}=90 \%
$$

A review of the two researchers' classification revealed that the small disagreement noted above $(10 \%)$ could be attributed to the fact that the problem structuring and problem solving cognitive phases are not always clearly distinguishable (Goel, 1995; Restrepo \& Christiaans, 2004). Stemler (2004) suggests that values ranging from $75 \%$ to $100 \%$ demonstrate a satisfactory level of credibility when determining inter-rater reliability based on the percentage of absolute agreement. Establishing an agreement between two sets of codings seemed to have resulted in credible inferences.

\section{Limitations}

Firstly, the small purposive sample does not allow for generalised statements to be made about the design process of all Grade 9 naïve designers. The selected groups of participants were of secondary importance, as our primary aim was to gain insight into the types of information sources naïve designers use to structure and solve their design problems (Yin, 2014). However, the possibility of certain tendencies being transferable to similar Technology classrooms does exist, as other low resource Technology classrooms might display a context and characteristics similar to the one described in detail in this article. Secondly, the sample that was selected by the Technology teacher only comprised female Grade 9 participants. The sample selection criteria focused primarily on the participants' ability to communicate effectively, but also on their ability to work together effectively as a group, and above average design capabilities. The sample criteria did not allow the teacher to discriminate between genders. Future studies could include stratified sampling criteria, which might include an equal distribution of male and female participants. Thirdly, the TAPS methodology that we used for collecting data was limited because it could not provide us with direct access to the internal information sources that the participants used during their design tasks. In order to compensate for this limitation, we collected multiple forms of external representations, including the participants' verbal utterances and their concurrent gesturing, sketching, writing, and 3D models. These multiple data sources allowed us to infer what internal information sources the participants were using. The multiple data sources also complemented each other, thereby validating the inferences that we made about the internal information sources that the participants used. Fourthly, the number of participants, uneven by accident, not design because of the withdrawal of one participant, might have influenced the frequency counts of cognitive phases and information sources. However, since the focus of this study was on the types of information sources used to structure and solve a design problem, this was not deemed to be problematic in terms of the reliability of the results.

\section{RESULTS}

Table 2 indicates that the participants in all three groups engaged predominantly in problem solving cognitive phases, as compared to problem structuring phases during their design processes. Reviewing the percentages of all three groups, problem structuring utterances constituted less than $20 \%$ of the verbal utterances of each group's design process. There did not seem to be an aberration in this regard in the group that only had two members.

Table 2. Frequency and percentage of utterances in each cognitive phase made by the groups of participants

\begin{tabular}{|c|c|c|c|c|}
\hline & & Frequency & Total utterances & Percentage \\
\hline \multirow{2}{*}{ Group A } & Problem structuring & 44 & \multirow{2}{*}{260} & 16.9 \\
\hline & Problem solving & 216 & & 83.1 \\
\hline \multirow{2}{*}{ Group B } & Problem structuring & 10 & \multirow{2}{*}{227} & 4.4 \\
\hline & Problem solving & 216 & & 95.1 \\
\hline \multirow{2}{*}{ Group C } & Problem structuring & 44 & \multirow{2}{*}{326} & 13.5 \\
\hline & Problem solving & 283 & & 86.8 \\
\hline
\end{tabular}

More than $80 \%$ of the total utterances in each group of participants focused on problem solving, indicating that the majority of the participants' design processes were dominated by design problem solving activities. The findings in design cognition suggest that expert designers spend the majority of their time focusing on understanding design problems, whereas novice designers tend to spend the majority of their time on developing solutions even when they have not yet understood their design problem (Kelley et al., 2015; Lawson \& Dorst, 2009; Welch, 1999). This finding implies that if Technology teachers want their learners to think more like expert designers, they need to facilitate learners to think about and represent their design problems more often.

In order to establish what sources each group of participants accessed and used during their cognitive phases, we counted the occurrences of the cognitive phases that each group of participants exhibited, as well as the information sources that they used. As such, we were able to describe what sources of information each group of participants used during problem structuring and solving respectively. Each of the groups' problem structuring 
and solving cognitive phases are visualised using bar graphs in Figures $\mathbf{1}$ and $\mathbf{2}$ to show the most prominent patterns of information sources accessed and used.

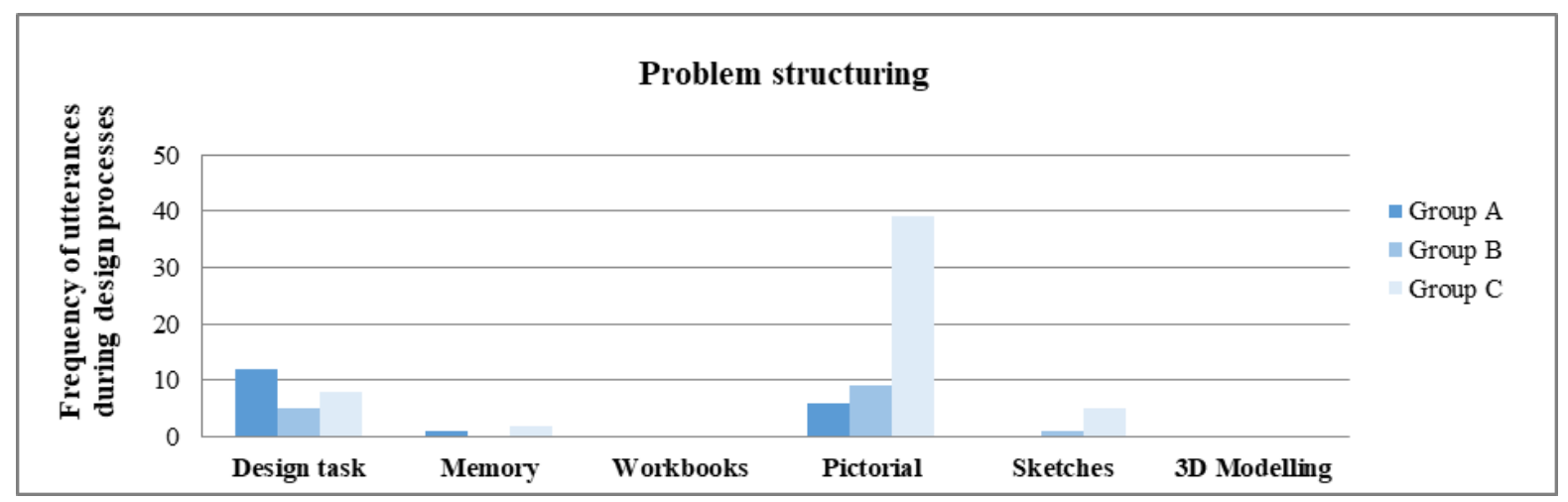

Figure 1. Frequencies of information use during problem structuring

In Figure 1, the data patterns reveal that the participants in this study predominantly used the design task and pictorial information during their problem structuring phases. Therefore, it seems as if the participants found information about the design problem and pictorial information more useful than their workbooks, sketches and 3D modelling materials to structure their design problems. This implies that these learners did not make their own representations of the design problem and relied predominantly on the information given in the design task, and pictorial information.

Figure 1 also indicates that the participants rarely accessed or used their workbooks or 3D modelling materials for problem structuring. This might have important implications for curriculum planning in Technology, since Technology textbooks do not necessarily contain sufficient information to allow participants to structure their design problems. If low-resource classrooms are instructed to solve design problems in their textbooks, then sufficient information should be made available to understand the context of the problem and the people involved, which will lead learners to formulate appropriate design objectives and constraints.

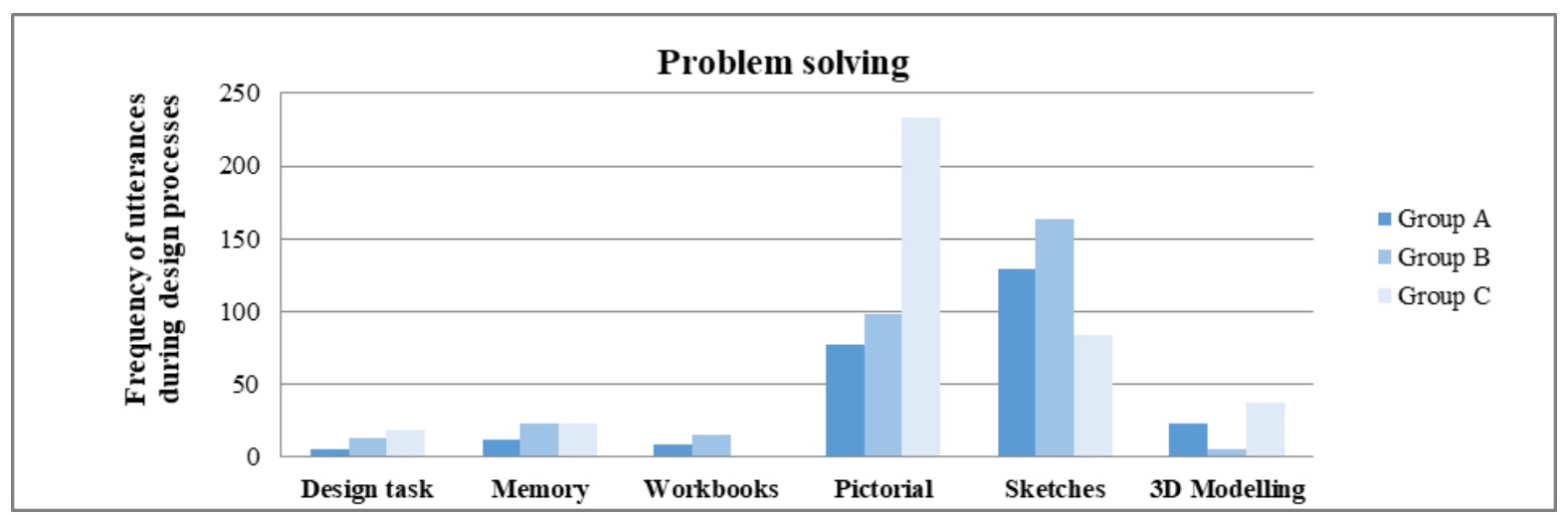

Figure 2. Frequencies of information use during problem solving

Figure 2 indicates that all three groups predominantly accessed and used external pictorial information and their sketches as information sources during problem solving. Therefore, the participants in this study relied predominantly on external sources of information to solve their design problem. Furthermore, Figure 2 also shows that the participants paid less attention to information sources, including prior knowledge, their workbooks and 3D modelling materials. Previous findings have shown that novice designers tend to engage in external information driven design (Kruger \& Cross, 2006) because they do not have the necessary prior experience in designing. When comparing the participants' proposed design ideas, we could see how the participants copied their ideas from existing solutions. Figures 3-5 reveal the similarities between external pictorial information and the groups of participants' proposed design ideas. 

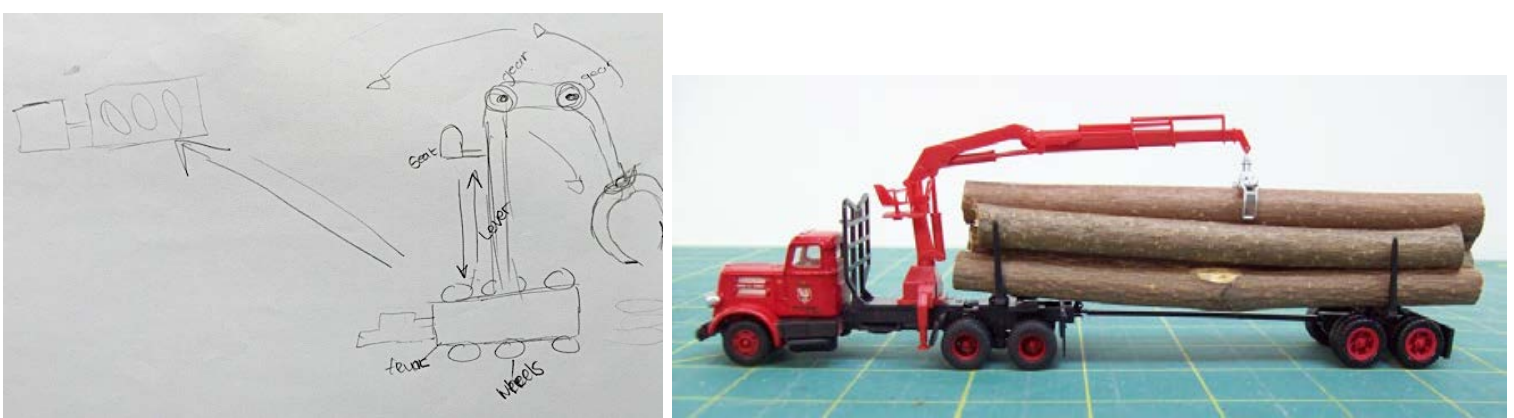

Figure 3. Group A's proposed design idea and the electrically powered crane on a truck (Figure 25 in Appendix A) on which it was based
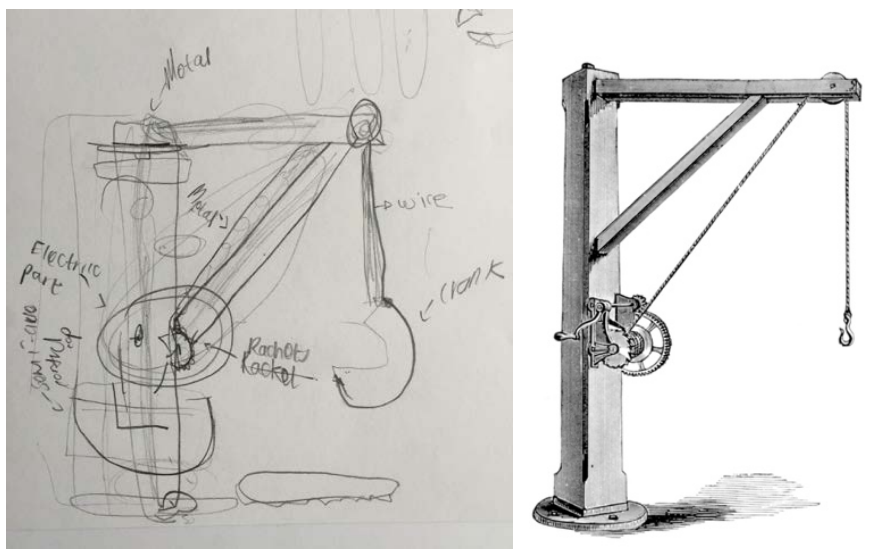

Figure 4. Group B's proposed design idea and the gear and crank system (Figure 14 in Appendix A) on which it was based
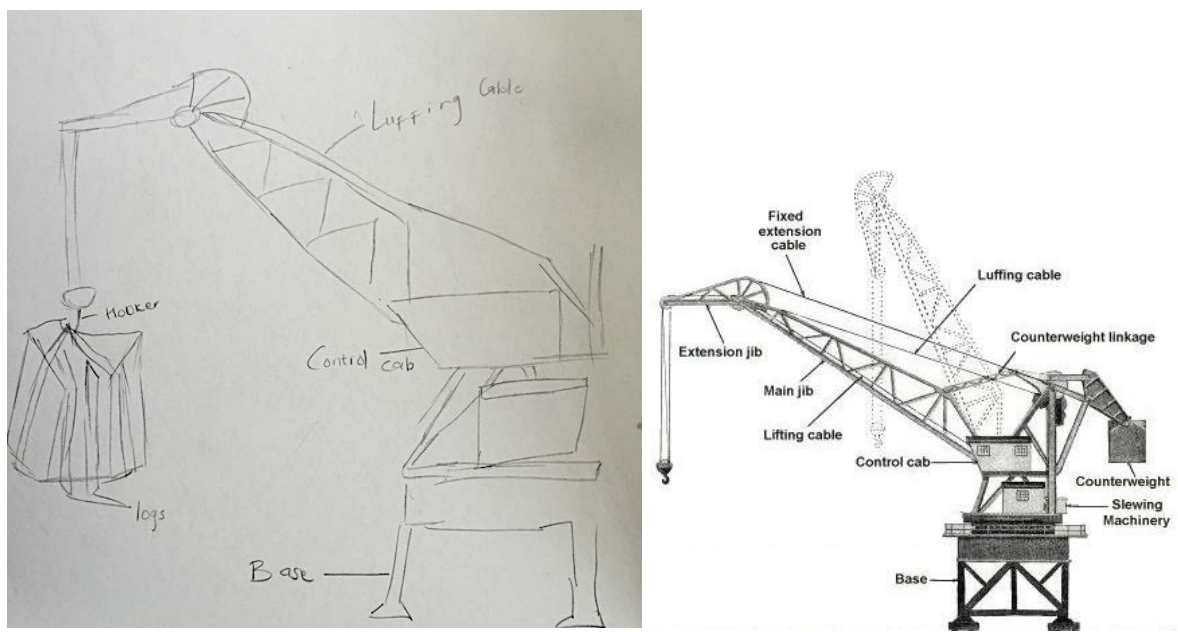

Figure 5. Group C's proposed design idea and the electrically powered crane (Figure 22 in Appendix A) on which it was based

In Figures 3-5 the similarity between the participants' final design ideas and the pictorial information on which their ideas were based, is illustrated. From an extended information processing view, it seems as if the pictures (see Appendix A) afforded the participants the information which they used to propose their design ideas. Although it might seem as if the participants just copied these ideas from pictures, extensive clarification and elaboration processes were evident in the protocols, but did not form part of the focus for this paper.

\section{Distribution of Cognitive Phases and Information Sources}

Hmelo-Silver, Chernobilsky and Jordan (2008) note that the frequencies of design actions provide only one view of learners' design processes, but do not provide context or information on particular design actions. In order to examine how the different information sources related to the participants' cognitive phases, we created three 


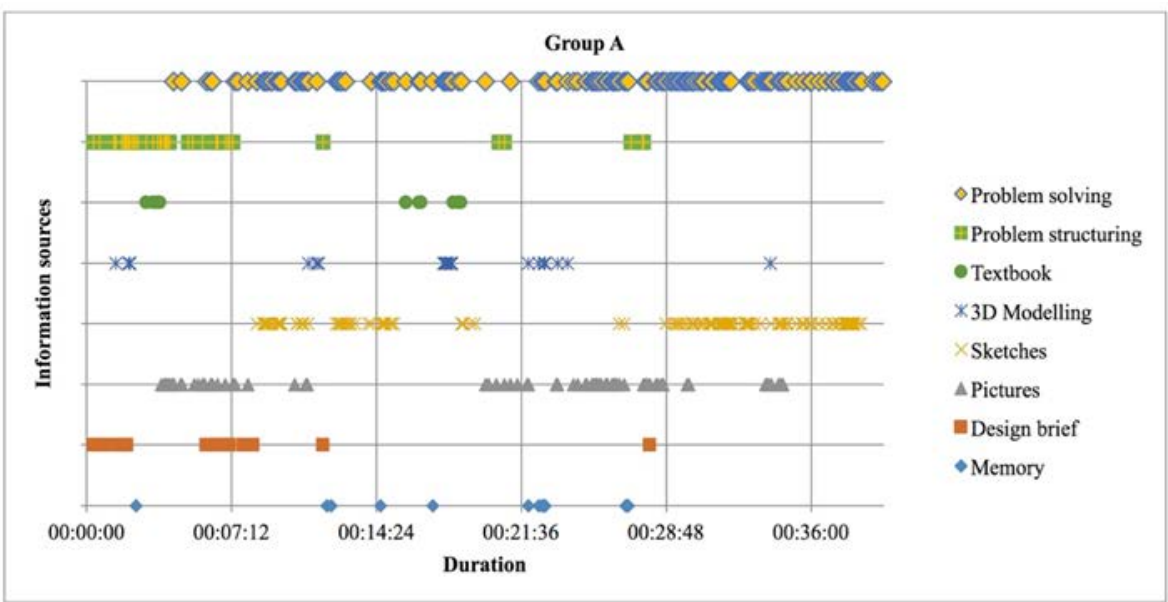

Figure 6. Distribution of Group A's cognitive phases and information sources

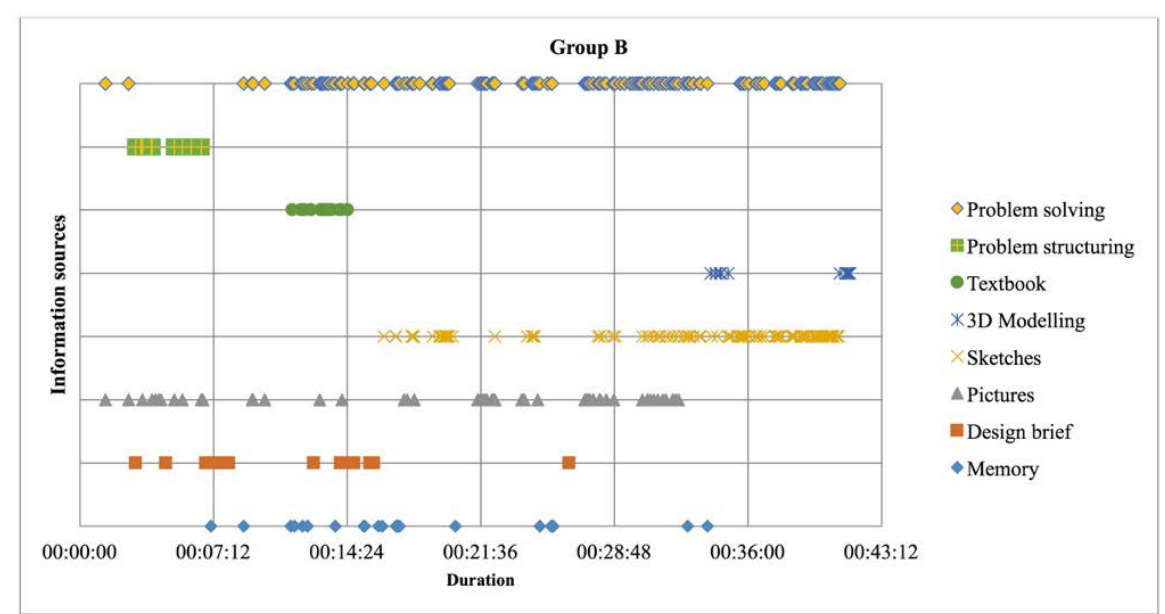

Figure 7. Distribution of Group B's cognitive phases and information sources

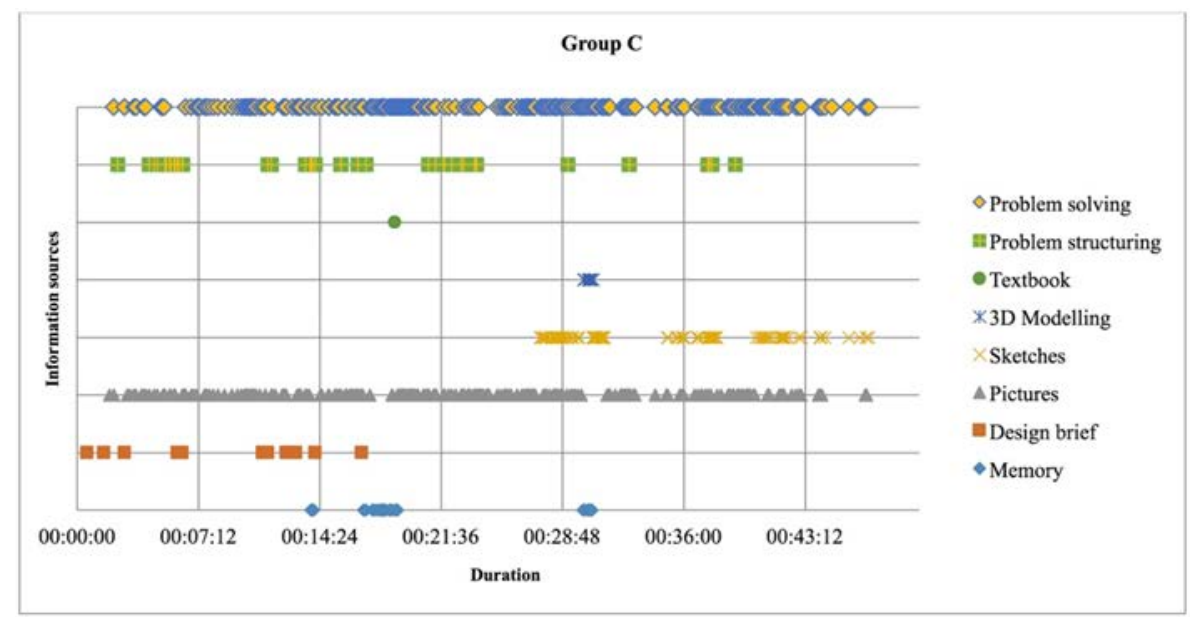

Figure 8. Distribution of Group C's cognitive phases and information sources

CORDTRA (Chronologically-Ordered Representation of Discourse and Tool Related Activity) diagrams to represent each participating group's design processes (see Figures 6-8).

In Figures 6-8, Group A and B had different patterns in the distribution of their problem structuring cognitive phases. While both Groups A and B primarily engaged in problem structuring at the beginning of their design 
processes, Group C continuously engaged in problem structuring during their design process. All three groups engaged in problem-solving cognitive phases throughout their design processes.

When focusing on the design task and the cognitive phases, it seems as if the design task was instrumental in facilitating all three groups to engage in problem structuring at the beginning of the design process. It appears, however, that the design brief was not considered throughout the participants' design processes, albeit for a few outliers. In advanced teaching methods for the Technology classroom, Petrina (2007) notes that the role of the design brief is to focus the efforts of learners on the design task, and is not a single-use document, i.e. the design brief should be used throughout the design process to ensure that the solutions that are generated and developed by designers actually fit the identified design problem. As such, it seems as if the participants only focused on the problem that they needed to address in the beginning of their design process without referring back to it during the middle or end of the design process. This finding confirms previous studies on Technology learners have evidenced how learners neglect to consider the problem they are addressing throughout their design process (Dixon \& Johnson, 2012; Hill \& Anning, 2001; Kimbell \& Stables, 2008).

When considering the distribution of pictorial information during the design process, it seems that all three groups used pictures throughout the problem structuring and solving phases. Previous studies on novice designers have shown consistently that novice designers prefer to use pictorial information as sources of inspiration during designing (Cash \& Gonçalves, 2017; Gonçalves et al., 2016; Gonçalves, Cardoso \& Badke-Schaub, 2014). As seen in Figures 3-5, when providing the participants with pictorial information regarding existing solutions, the participants copied the ideas. However, providing pictures of existing solutions might have stifled the participants' own creative behaviours (McLellan \& Nicholl, 2011).

\section{DISCUSSION}

The first finding of this study indicated that the participants predominantly engaged in problem solving rather than problem structuring cognitive phases. This was expected since naïve designers do not have sufficient prior experience and knowledge to understand their design problem context or to recognise the complexity of the design issues to be addressed. Findings focusing on the early phases of designing indicate that the behaviour of Technology learners often differs from that of expert designers in terms of time spent on problem structuring and evaluation (Atman et al., 2007; Kelley et al., 2015; Mohedas et al., 2015).

Another finding revealed that the participants rarely accessed information from their memory to structure or solve their design problem. One reason for this could be the participants' lack of information and exposure to the problem context of the design task. It is unlikely that the participants understood the problem context, because they had limited prior knowledge and experience with such mechanical design problems. Furthermore, prior research in a South African context shows that teachers do not attempt to contextualise textbook content for learners (Ramaligela, Gaigher \& Hattingh, 2014), a fact which may lie at the basis of this finding. Although the participants were engaged in 10 weeks of instruction on mechanical systems and control, they struggled to transfer the knowledge and skills acquired in 10 weeks of instruction to the given design task. Extended information processing theory, then, allowed us to study how the participants compensated for their lack of internally stored knowledge and experience by using information from external information sources.

By relying on an extended information processing view on the data we found that pictorial information and sketches were the most consistently used. This made sense, because the pictures provided information about the design context and existing solutions. Furthermore, pictorial information may be the only way in which the participants from a low-resource school could have access to the context of the design problem and existing solutions. Unfortunately, there are limited empirical findings on the way in which naïve designers actually use pictorial information during the design process (Gonçalves et al., 2016; Gonçalves et al., 2014).

The participants' use of sketches could potentially be explained by Dorst and Lawson's (2009) levels of design expertise. While the participants used sketching extensively, their sketching was mainly based on understanding and copying from existing solutions which they perceived in pictorial information. Since the participants of this study did not have sufficient prior knowledge or experience in design contexts featuring mechanical systems, this behaviour was predictable. Future studies might gain insight into how naïve designers transform existing ideas from pictorial information into novel design solutions.

\section{IMPLICATIONS}

In this study, the participants tended to spend more time solving as opposed to structuring their design problem. Teachers might want to consider how to facilitate between problem structuring and problem solving, as is done by expert designers, when they see that learners do not have sufficient understanding of their design problem. By asking hinge-point questions (William, 2011) or engaging in Socratic questioning throughout the 
design process, teachers can easily gauge whether learners understand fundamental design issues and concepts to be addressed during their PAT. Since naïve designers do not yet possess prior knowledge or experience to solve design problems on their own, it is necessary for teachers to facilitate ways of thinking and knowing mirroring expert designing.

If learners do not readily access and use information from their memory to structure or solve their design problem, it may mean that the content taught during enabling tasks, prior to the PAT, was not contextualised in a way that seems useful. Prior research findings that show that some South African teachers do not contextualise learning content for learners (Ramaligela et al., 2014), as well as the fact that expert designers predominantly rely on domain specific knowledge stored in their memory, indicate that teachers should model how previously learned concepts in enabling tasks are necessary for success in the PATs. Since the mechanical systems learning content prescribed by the Technology curriculum is devoid of context, and mainly based on physics, it remains the responsibility of the Technology teacher to contextualise learning content.

If learners are not able to access and use information located in their memory, they will search for information in the external environment. This was seen in this study in the participants' predominant use of pictorial information and sketches to solve their design problems. Since naïve designers do not yet have the internally stored prior knowledge and experience, it is imperative that effective external sources of information are suggested, either by curriculum developers, textbook writers or teachers for use during learners' PATs. However, simply providing examples of existing solutions enhances participants' copying of ideas. Therefore, further research may show how advanced beginner, competent and proficient designers (Lawson \& Dorst, 2009) interact with external information, and so enhance understanding of how novel ideas emerge.

\section{CONCLUSION}

The purpose of this paper was not to generalise its findings, but to identify the internal and external information sources that Grade 9 Technology learners from a low-resource school used during a mechanical systems and control design task. The Extended Information Processing Theory guided us to identify what internal and external information sources the participants in this case study used during problem structuring and problem solving. Describing each participating group's design process from an extended information processing viewpoint allow opportunities for demonstrating how design thinking is a rational activity in which information sources are purposefully and intentionally used for designing. This implies that teachers can effectively support learners' design processes by showing and manipulating existing information sources, or by reminding learners of prior knowledge to structure and solve their design problems. Finding empirical evidence regarding what information sources naive designers use during design tasks might contribute to better facilitation of the design process in Technology classrooms. If we want Technology learners to develop higher-order design cognition, we should encourage current and future teachers to design and provide meaningful learning environments in which learners are exposed to various information sources during their design tasks. During learners' design tasks, teachers should scaffold learners' design processes by introducing or reminding learners of valuable information on which to base their design decisions. Failing to scaffold learners' design processes with information sources might result in learning failures characterised by common and predictable design solutions due to a lack of critical thinking. As such, learners should be guided to make informed design decisions based on appropriate contextual, theoretical, and practical information in order to prevent superficial design solutions.

\section{ACKNOWLEDGEMENTS}

The financial support of the National Research Foundation (NRF) of South Africa is hereby acknowledged and appreciated. Opinions expressed and conclusions arrived at are those of the authors and may not necessarily be attributed to the above mentioned institutions.

\section{REFERENCES}

Abbey, S. K. (2008). Modelling socio-economic dynamics in a working-class desegregation area in post-industrial, postapartheid South Africa - the case of Danville-Elandspoort (Doctoral thesis), University of Pretoria, Pretoria.

Atman, C., Adams, R., Mosborg, S., Cardella, M., Turns, J., \& Saleem, J. (2007). Engineering design processes: a comparison of students and expert practitioners. Journal of Engineering Education, 96. https:/ / doi.org/10.1002/j.2168-9830.2007.tb00945.x

Björklund, T. A. (2013). Initial mental representations of design problems: Differences between experts and novices. Design Studies, 34(2), 135-160. Retrieved from http:/ / doi.org/10.1016/j.destud.2012.08.005 
Bursic, K. M., \& Atman, C. J. (1997). Information gathering: a critical step for quality in the design process. The Quality Management Journal, 4(4), 60-75. https:/ / doi.org/10.1080/10686967.1998.11919148

Cash, P., \& Gonçalves, M. (2017). Information-triggered Co-evolution: A Combined Process Perspective. In B.T. Christensen, L.J. Ball \& K. Halskov (Eds.). Analysing Design Thinking: Studies of Cross-Cultural Co-Creation (pp. 501 - 520). London: CRC Press.

Cash, P., Hicks, B., \& Culley, S. (2015). Activity Theory as a means for multi-scale analysis of the engineering design process: A protocol study of design in practice. Design Studies, 38, 1-32. Retrieved from https://doi.org/10.1016/j.destud.2015.02.001

Clark, A. (2006). Soft Selves and Ecological Control. In D. Spurrett, D. Ross, H. Kincaid \& L. Stephens (Eds.), Distributed Cognition and the Will (pp. 101 -122). Cambridge MA: The MIT Press.

Clark, A. (2008). Supersizing the Mind: Embodiment, Action, and Cognitive Extension. New York: Oxford University Press.

Clark, A., \& Chalmers, D. (1998). The extended mind. Analysis, 58, 10-23. https:/ / doi.org/10.1093/analys/58.1.7

Clitheroe, F., Goosen, A., Kathan, V., Mlambo, T., Roebert, M., Sargeant, I., \& Walstra, K. (2013). Platinum Technology. Cape Town: Maskew Miller Longman.

Creswell, J. W. (2014). Research Design: Qualitative, Quantitative and Mixed Methods Approaches. Lincoln, USA: SAGE Publications.

Csapó, B., \& Funke, J. (2017). The development and assessment of problem solving in 21st-century schools. In B. Csapó, \& J. Funke (Eds.), The nature of problem solving: Using research to inspire 21st century learning. https:/ / doi.org/10.1787/9789264273955-en

DBE. (2011). Curriculum and Assessment Policy Statement. Senior Phase: Technology. Republic of South Africa: South African Department of Basic Education.

DBE. (2018). National Education Infrastructure Management System. Retrieved from https:/ / www.education.gov.za/Portals/0/Documents/Reports /NEIMSReport20172018.pdf?ver=201801-30-120305-787

De Vries, M. (2016). Teaching about Technology. An Introduction to the Philosophy of Technology for Non-philosophers. Dordrecht: Springer.

Dinar, M., Shah, J., Cagan, J., Leifer, L., Linsey, J., Woodruff, G., \& Vargas Hernandez, N. (2015). Empirical Studies of Designer Thinking: Past, Present, and Future. Journal of Mechanical Design, 137, 1-13. Retrieved from https://doi.org/10.1115/1.4029025

Dixon, R. A, \& Johnson, S. D. (2012). The Use of Executive Control Processes in Engineering Design by Engineering Students and Professional Engineers. Journal of Technology Education, 24(1), 73-89. Retrieved from http:/ / scholar.lib.vt.edu/ ejournals/JTE/v24n1/dixon2.html

Dorst, K., \& Cross, N. (2001). Creativity in the design process: co-evolution of problem-solution. Design Studies, 22(5), 425-437. https:/ / doi.org/10.1016/S0142-694X(01)00009-6

Dym, C. L., Little, P., \& Orwin, E. J. (2014). Engineering Design: A Project based approach (4th ed.). United States of America: John Wiley \& Sons.

Ericsson, K. A., \& Simon, H. A. (1993). Protocol analysis: Verbal reports as Data (2nd ed.). Cambridge, MA: MIT Press.

Gero, J. (1998). Towards a Model of Designing Which Includes its Situatedness. In H. Grabowski, S. Rude, \& G. Grein (Eds.), Universal Design Theory (pp. 47-56). Aachen: Shaker Verlag.

Goel, V. (1995). Sketches of Thought. Cambridge, MA: MIT Press.

Goel, V. (2014). Creative brains: designing in the real world. Frontiers in Human Neuroscience, 8(April), 241. Retrieved from https:/ / doi.org/10.3389/fnhum.2014.00241

Goldschmidt, G., \& Rodgers, P. A. (2013). The design thinking approaches of three different groups of designers based on self-reports. Design Studies, 34(4), 454-471. https:/ / doi.org/10.1016/j.destud.2013.01.004

Gonçalves, M., Cardoso, C., \& Badke-Schaub, P. (2013). Inspiration peak: exploring the semantic distance between design problem and textual inspirational stimuli. International Journal of Design Creativity and Innovation, 1(4), 215-232. https:/ / doi.org/10.1080/21650349.2013.799309

Gonçalves, M., Cardoso, C., \& Badke-Schaub, P. (2014). What inspires designers? Preferences on inspirational approaches during idea generation. Design Studies, 35(1), 29-53. https:/ / doi.org/http:/ / dx.doi.org/10.1016/j.destud.2013.09.001

Gonçalves, M., Cardoso, C., \& Badke-Schaub, P. (2016). Inspiration choices that matter: the selection of external stimuli during ideation. Design Science, 2. https:/ / doi.org/10.1017/dsj.2016.10 
Grubbs, M., \& Strimel, G. (2016). Cognitive Research: Transferring Theories and Findings to K-12 Engineering Educational Practice. In the American Society for Engineering Education 103rd Annual Conference and Exposition. New Orleans, LA: American Society for Engineering Education.

Haupt, G. (2015). Learning from experts: fostering extended thinking in the early phases of the design process. International Journal of Technology and Design Education, 25(4), 483-520. http:/ / doi.org/10.1007/s10798-0149295-7

Haupt, G. (2018). Hierarchical thinking: a cognitive tool for guiding coherent decision making in design problem solving. International Journal of Technology and Design Education, 28(1), 207-237. http:/ / doi.org/10.1007/s10798-016-9381-0

Hay, L., Duffy, A., McTeague, C., Pidgeon, L., Vuletic, T., \& Grealy, M. (2017). A systematic review of protocol studies on conceptual design cognition: Design as search and exploration. Design Science, 3, 1-36. http:/ / doi.org/10.1017/dsj.2017.11

Heisig, P., Caldwell, N. H. M., Grebici, K., \& Clarkson, P. J. (2010). Exploring knowledge and information needs in engineering from the past and for the future - results from a survey. Design Studies, 31(5), 499-532. https:/ / doi.org/10.1016/J.DESTUD.2010.05.001

Hill, A. M., \& Anning, A. (2001). Comparisons and Contrasts between Elementary/Primary School Situated Design and Workplace Design in Canada and England. International Journal of Technology and Design Education, 11(2), 111-136.

Hmelo-Silver, C., Chernobilsky, E., \& Jordan, R. (2008). Understanding collaborative learning processes in new learning environments. Instructional Science. Springer. https:/ / doi.org/10.2307/23372648

Hutchins, E. (2014). The cultural ecosystem of human cognition. Philosophical Psychology, 27(1), $34-49$. https:// doi.org/10.1080/09515089.2013.830548

Jin, Y., \& Benami, O. (2010). Creative patterns and stimulation in conceptual design. Artificial Intelligence for Engineering Design, Analysis and Manufacturing, 24(2), 191. https://doi.org/10.1017/S0890060410000053

Johnstone, H., Mitchley, A., Schreuder, B., Sherwood, R., Snyman, E., \& Ter-Morshuizen, K. (2013). Technology Today Gr. 9. South Africa. South Africa: Maskew Miller Longman.

Jonassen, D. H. (2011). Design problems for secondary students. Retrieved from http:/ / digitalcommons.usu.edu/ncete_publications/164

Kelley, T., Capobianco, B., \& Kaluf, K. (2015). Concurrent think-aloud protocols to assess elementary design students. International Journal of Technology and Design Education, 25(4), 521-540. http:/ / doi.org/10.1007/s10798-014-9291-y

Kim, J., \& Ryu, H. (2014). A Design Thinking Rationality Framework: Framing and Solving Design Problems in Early Concept Generation. Human-Computer Interaction, 29(5-6), 516-553. https:/ / doi.org/10.1080/07370024.2014.896706

Kimbell, R., \& Stables, K. (2008). Researching Design Learning. Dordrecht, The Netherlands: Springer.

Kola, M. I. (2017). Technology Teacher Trainees' Lesson Planning Approach in South Africa: Room for Improvement. African Journal of Research in Mathematics, Science and Technology Education, 21(3), 293-303. https:/ / doi.org/10.1080/18117295.2017.1379215

Kruger, C., \& Cross, N. (2006). Solution driven versus problem driven design: Strategies and outcomes. Design Studies, 27(5), 411-435. https:/ / doi.org/10.1016/j.destud.2006.01.001

Lawson, B., \& Dorst, K. (2009). Design Expertise. Oxford: Architectural Press.

Mathumbu, D., Rauscher, W., \& Braun, M. (2014). Knowledge and cognitive process dimensions of Technology teachers' lesson objectives. South African Journal of Education, 34(3), 01-09. Retrieved from http://0www.scielo.org.za.innopac.up.ac.za/scielo.php?script=sci_arttext\&pid=S0256-

01002014000300009\&lng=en\&nrm=iso\&tlng=es

McLellan, R., \& Nicholl, B. (2011). "If I was going to design a chair, the last thing would look at is a chair": Product analysis and the causes of fixation in students' design work 11-16 years. International Journal of Technology and Design Education, 21(1), 71-92. https:/ / doi.org/10.1007/s10798-009-9107-7

Menary, R. (2007). Cognitive Integration: Mind and cognition unbounded. Basingstoke: Palgrave Macmillan.

Menary, R. (2010). Dimensions of Mind. Phenomenology and the Cognitive Sciences, 9, 561-578.

Mettas, A., \& Norman, E. (2011). A grounded theory approach to the development of a framework for researching children's decision-making skills within design and technology education. Design and Technology Education: An International Journal, 16, 8-19. 
Mohedas, I., Daly, S., \& Sienko, K. (2015). Requirements Development: Approaches and Behaviors of Novice Designers. Journal of Mechanical Design, 137(7), 71407. https:/ / doi.org/10.1115/1.4030058

Naidoo, K. (2011). Poverty and socio-political transition: perceptions in four racially demarcated residential sites in Gauteng. Development Southern Africa, 22(2), 277-290.

Newell, A., \& Simon, H. (1972). Human problem solving. Englewood Cliffs, NJ: Prentice-Hall.

Nicholl, B., \& Mclellan, R. (2005). “Oh yeah, yeah you get a lot of love hearts. The year 9s are notorious for love hearts. Everything is love hearts." Fixation in pupils' design and technology work (11-16 years). Design and Technology Education: An International Journal, 12(1), 34-44.

Oxman, R. (2001). The mind in Design: A conceptual Framework for Cognition in Design Education. In C. Eastman, M. McCracken, \& W. Newstetter (Eds.), Design knowing and learning: Cognition in Design Education (pp. 269297). Oxford: Elsevier.

Petrina, S. (2007). Advanced Teaching Methods for the Technology Classroom. Information Science Publishing. Retrieved from http:/ / eric.ed.gov/?q=\%2522Petrina+Stephen\%2522\&ff1=pubBooks\&id=ED508836

Petrina, S. (2010). Cognitive Science. In P. A. Reed \& J. E. LaPorte (Eds.), Research in Technology Education: 59th Yearbook. United States of America: Council on Technology Teacher Education.

Petrina, S., Feng, F., \& Kim, J. (2008). Researching cognition and technology: how we learn across the lifespan. International Journal of Technology and Design Education, 18, 375-396. https://doi.org/10.1007/s10798-0079033-5

Pieper, J. (2013). High School Students' Use of Paper-Based and Internet-Based Information Sources in the Engineering Design Process. Journal of Technology Education, 24(2), 78-95.

Ramaligela, M. S., Gaigher, E., \& Hattingh, A. (2014). Exploring the use of Technology textbooks in medium- and well-resourced school contexts in South Africa. Africa Education Review, 11(2), 183-200. https:/ / doi.org/10.1080/18146627.2014.927156

Reed, S. K. (2016). The Structure of Ill-Structured (and Well-Structured) Problems Revisited. Educational Psychology Review, 28(4), 691-716. https:/ / doi.org/10.1007/s10648-015-9343-1

Restrepo, J. (2006). Studying Design Engineers use of Information Systems: Which variables to control for. Design Research Society International Conference, Lisbon.

Restrepo, J., \& Christiaans, H. (2004). Problem Structuring and Information Access in Design. The Journal of Design Research, 4(2). https:/ / doi.org/10.1504/JDR.2004.009842

Robbins, P., \& Aydede, M. (2009). A Short primer on situated cognition. In P. Robbins \& M. Aydede (Eds.), The Cambridge Handbook of Situated Cognition (pp. 3 - 10). New York: Cambridge University Press.

Robertson, I. (2017). Problem solving: Perspectives from Cognition and Neuroscience (2nd ed.). London: Routledge.

Simon, H. A. (1973). The structure of ill structured problems. Artificial Intelligence, 4(3-4), 181-201. https:/ / doi.org/10.1016/0004-3702(73)90011-8

Song, T., Becker, K., Gero, J., DeBerard, S., Lawanto, O., \& Reeve, E. (2016). Problem Decomposition and Recomposition in Engineering Design: a Comparison of Design Behavior between Professional Engineers, Engineering Seniors, and Engineering Freshmen. Journal of Technology Education, 27(1). https://doi.org/10.21061/jte.v27i2.a.3

Stables, K. (2010). The Inspiration Pitch: Where do design ideas come from? In The Design and Technology Association Research Conference (pp. 111-121). United Kingdom: Keele University.

Stemler, S. E. (2004). A comparison of consensus, consistency, and measurement approaches to estimating interrater reliability. Practical Assessment, Research E Evaluation, 9(4).

Strimel, G., \& Grubbs, M. (2017). A Critical Examination of Engineering Design Processes and Procedures. In L. Litowitz \& S. Warner (Eds.), Technology and engineering education: Fostering the creativity of youth around the globe. Philadelphia, PA: Millersville University.

Summers, J. D., Joshi, S., \& Morkos, B. (2014). Requirements evolution: Relating functional and non-functional requirement change on student project success. International Design Engineering Technical Conferences and Computers and Information in Engineering Conference, Buffalo.

Teddlie, C., \& Tashakkori, A. (2009). Foundations of Mixed Methods Research: Integrating Quantitative and Qualitative Approaches in the Social and Behavioural Sciences. Thousand Oaks, CA: SAGE.

Trudell, B. (2007). Local community perspectives and language of education in sub-Saharan African communities. International Journal of Educational Development, 27(5), 552-563. https:/ / doi.org/10.1016/J.IJEDUDEV.2007.02.002 
Ullman, D., Dietterich, T., \& Stauffer, L. (1988). A model of the mechanical design process based on empirical data. AI EDAM, 2(1), 33-52.

Visser, W. (2009). Design: one, but in different forms. Design Studies, 30(3), 187-223. https://doi.org/10.1016/j.destud.2008.11.004

Welch, M. (1999). Analyzing the Tacit strategies of Novice Designers. Research in Science E Technological Education, 17(1), 19-34. https:/ / doi.org/10.1080/0263514990170102

Welch, M., \& Lim, H.S. (2000). The strategic thinking of novice designers: discontinuity between theory and practice. The Journal of Technology Studies, 26. https:/ / doi.org/10.21061/jots.v26i2.a.6

Wells, J. G., Lammi, M., Gero, J., Grubbs, M., Paretti, M., \& Williams, C. (2016). Characterizing design cognition of high school students: Initial analyses comparing those with and without pre-engineering experiences. Journal of Technology Education, 27(April), 78-91. https:/ / doi.org/10.21061/jte.v27i2.a.5

William, D. (2011). Embedded formative assessment. Bloomington, IN: Solution Tree.

Wu, Q., \& Wang, Y. (2015). To explore the effect of sub consciousness on Sudden Moments of Inspiration (SMI) in the sketching process of industrial design. International Journal of Technology and Design Education, 25(4), 563584. https:/ / doi.org/10.1007/s10798-015-9326-Z

Yin, R. (2014). Case Study Research: Design and Methods (5th ed.). Los Angeles: SAGE. 


\section{APPENDIX A}

\section{The Design Task}

Name:

Participant:

\section{Problem Statement}

A timber company cuts down trees in a forest and uses trucks to transport the logs to a nearby sawmill. It takes very long for workers to manually load the logs onto a truck one by one. The company needs a machine that can pick up logs from the ground and transfer them onto a truck quickly and safely.
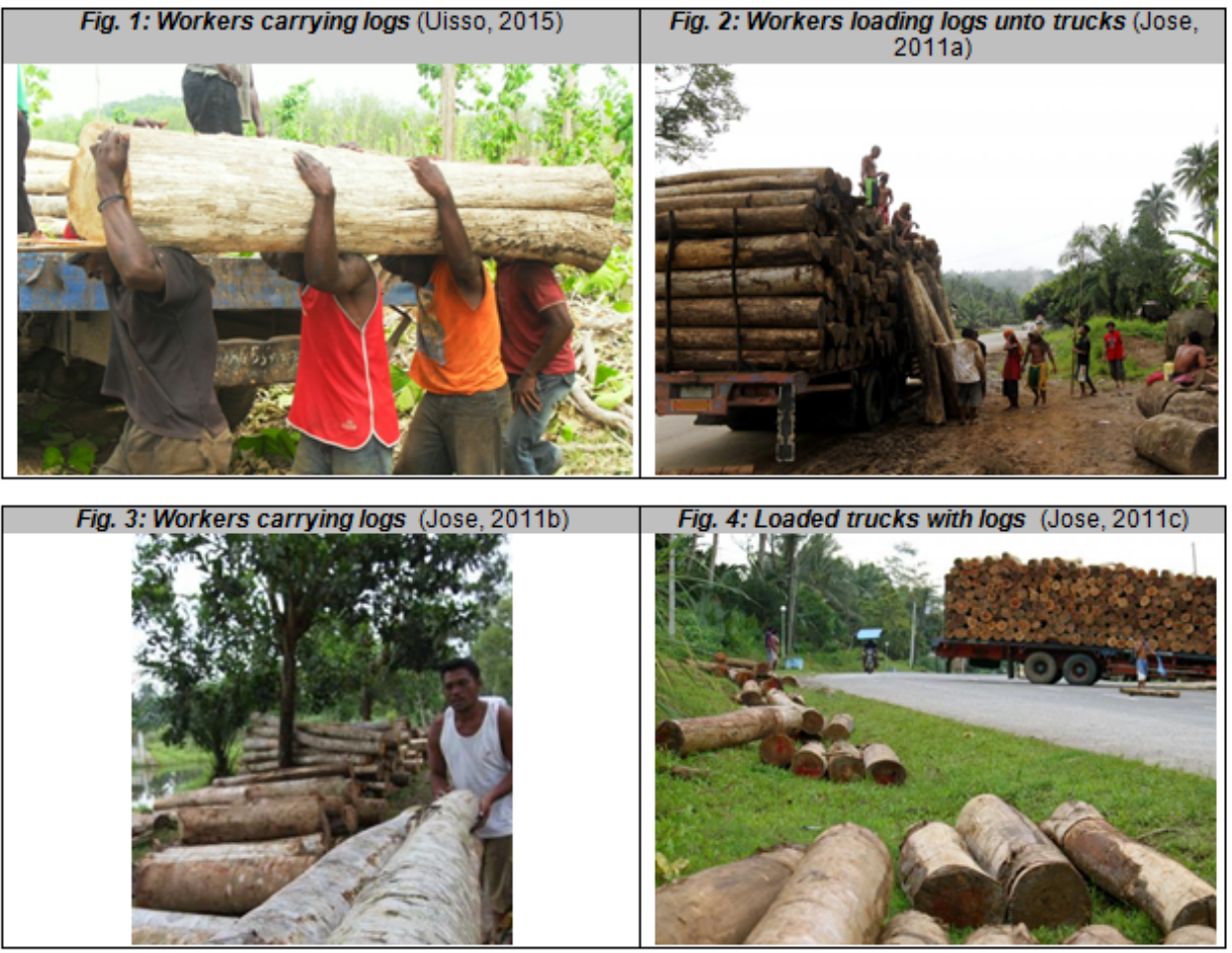

\section{Design task}

Design a model of a machine that can pick up logs from the ground and transfer them onto the transport truck. You only have to design the lifting machine, not the truck.

Most machines consist of several mechanisms that are combined to do a task. Your model must consist of at least two sub-systems:

- One of the sub-systems must consist of one or more mechanism that give mechanical advantage, such as levers, linkages, wheels, cams, cranks, pulleys, gears, hydraulic or pneumatic systems.

- The other sub-system must control the movements of the machine. Safety requirements demand that a load must not fall when the effort is removed. If the lifting process is interrupted for some reason, gravity may cause the load to drop back again. This could damage the load or the mechanical system, or it may hurt people nearby. Your design must include a mechanical control system such as a cleat, or a ratchet and pawl, to prevent the reverse action and/stop the movement. 


\section{Instructions}

In this design task, you will be working in a group. You are required to design a machine that can load logs onto a truck. Throughout the design task you may use information from your memory, textbook, workbook and cell phone if you need it. You are also allowed to highlight, make notes and draw sketches on all the pictures and notes given to you.

1. Consider the environment in which the machine must function. Discuss the following questions: (15 minutes)

- How will the environment in which the machine will operate affect its operation?

- Will the machine always stay in the same position?

- How high will it have to lift the logs?

- How will you ensure that the machine will not topple over?

- How will the machine make work quicker and faster?

2. Think about the movements your machine will need to perform. Which mechanisms can you use to? (20 Minutes)

- Pick up and hold the logs

- Lift the logs

- Create different movement in different parts of the machine

- Control the movements of the machine (Gravity may cause the load to drop back and be damaged. Consider how to incorporate a control mechanism in your machine to stop this from happening).

- Move the machine around, if necessary

Make as many notes of your ideas by writing and drawing rough preliminary sketches with arrows and labels to describe movements.

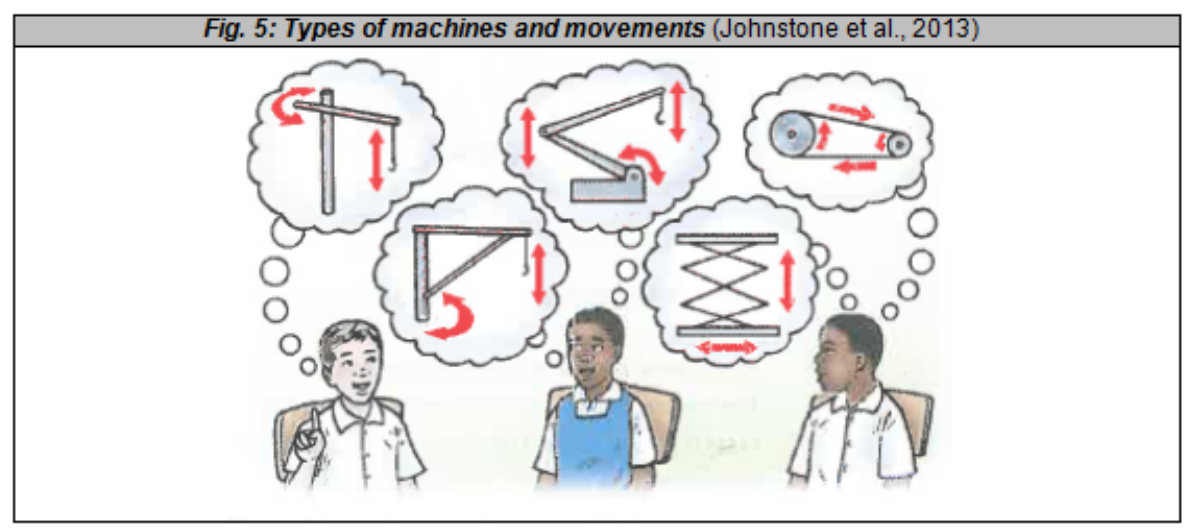

3. Suggest at least two possible designs that will be able to transfer logs from the ground onto a truck. (25 minutes) 

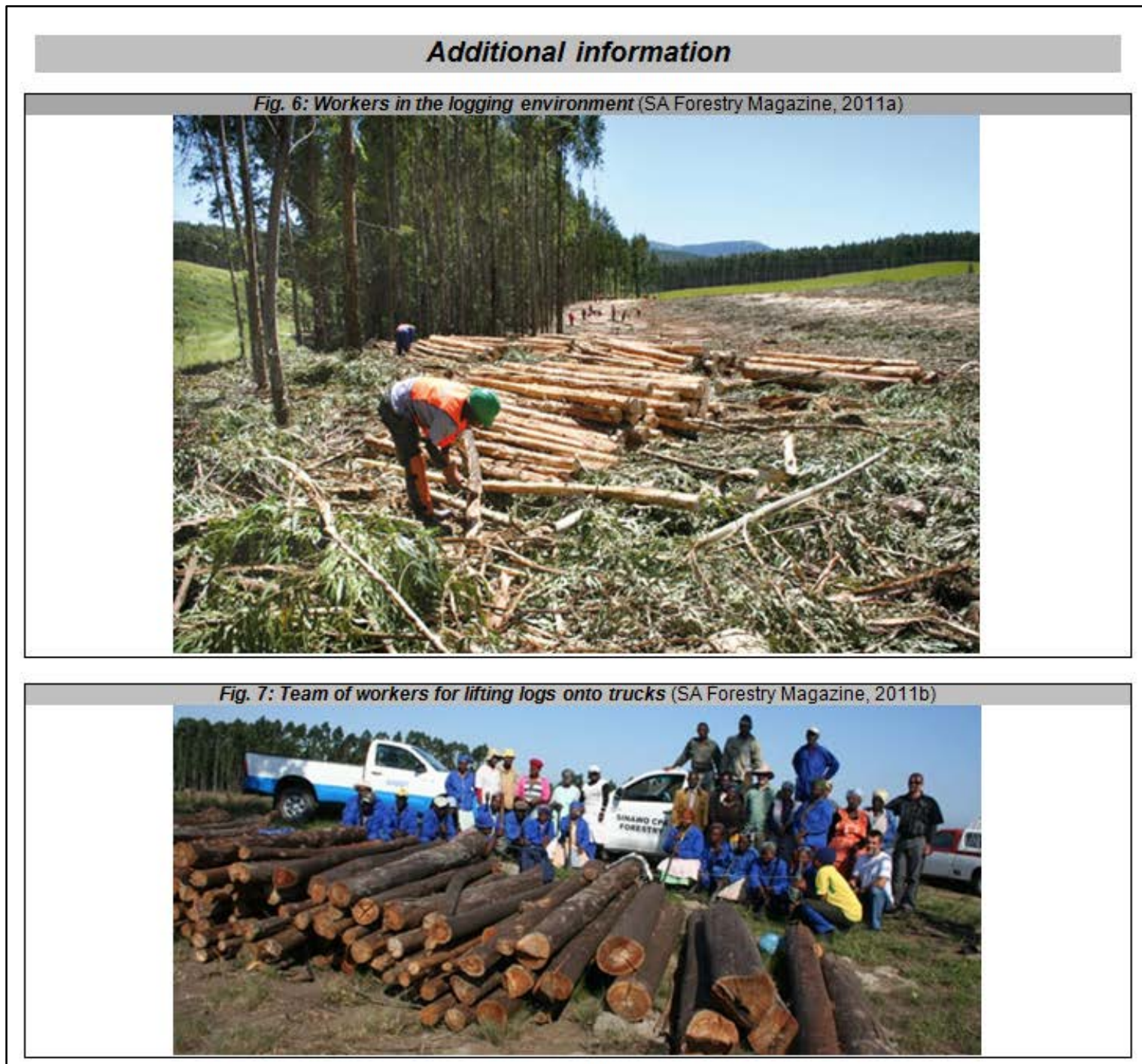

Fig. 8: Person packing and arranging logs on the truck (Logging on, 2009)

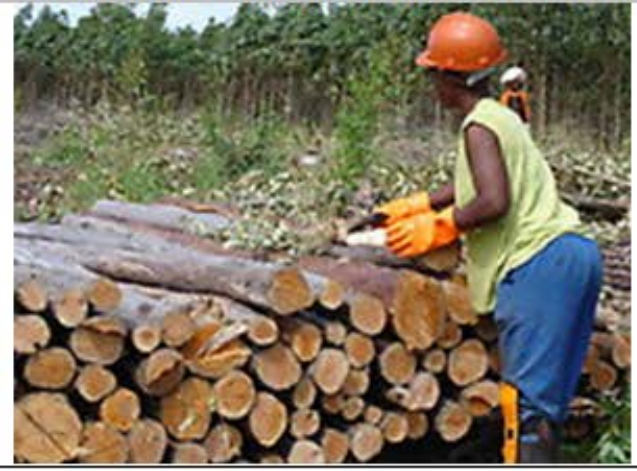



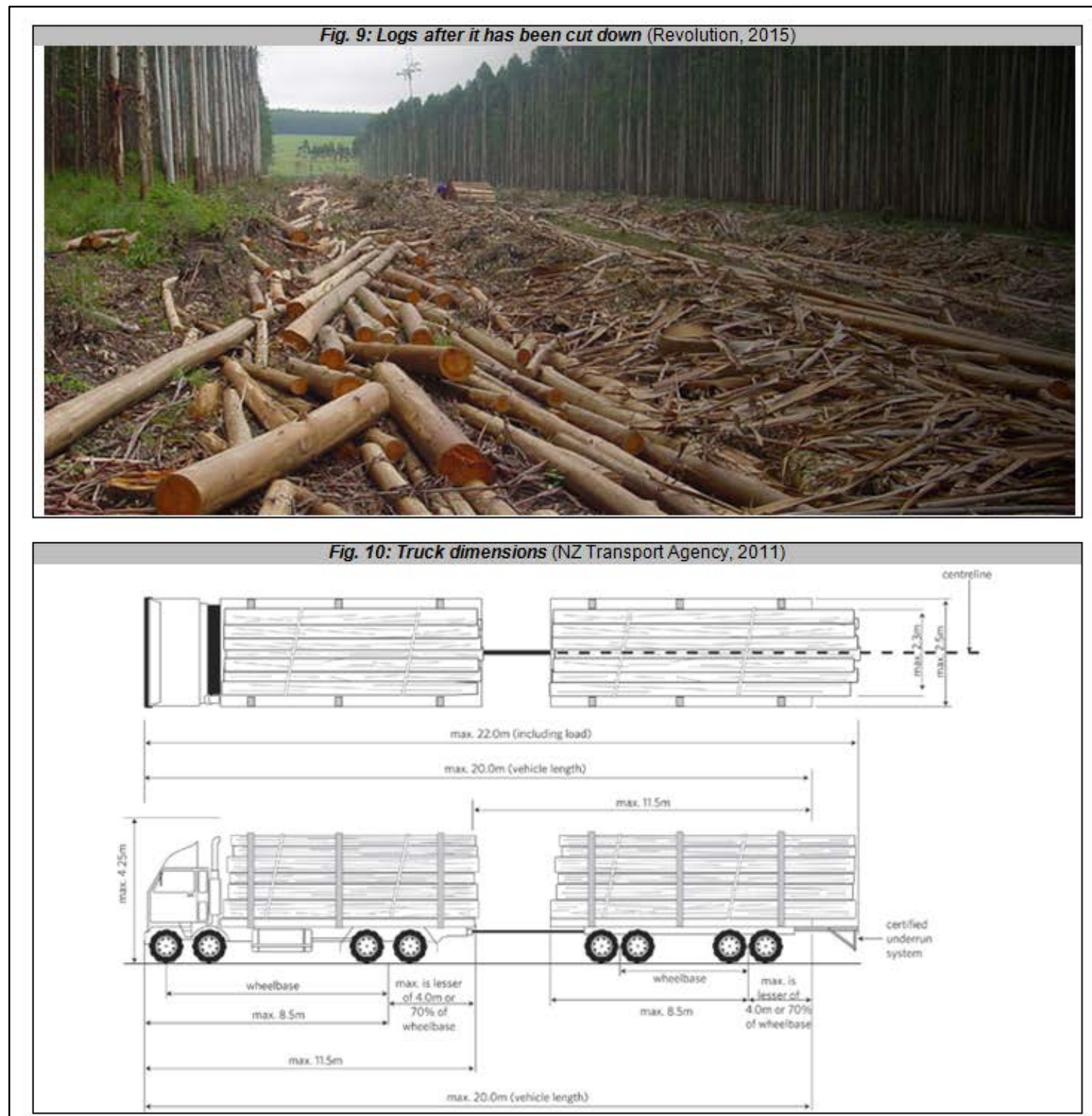

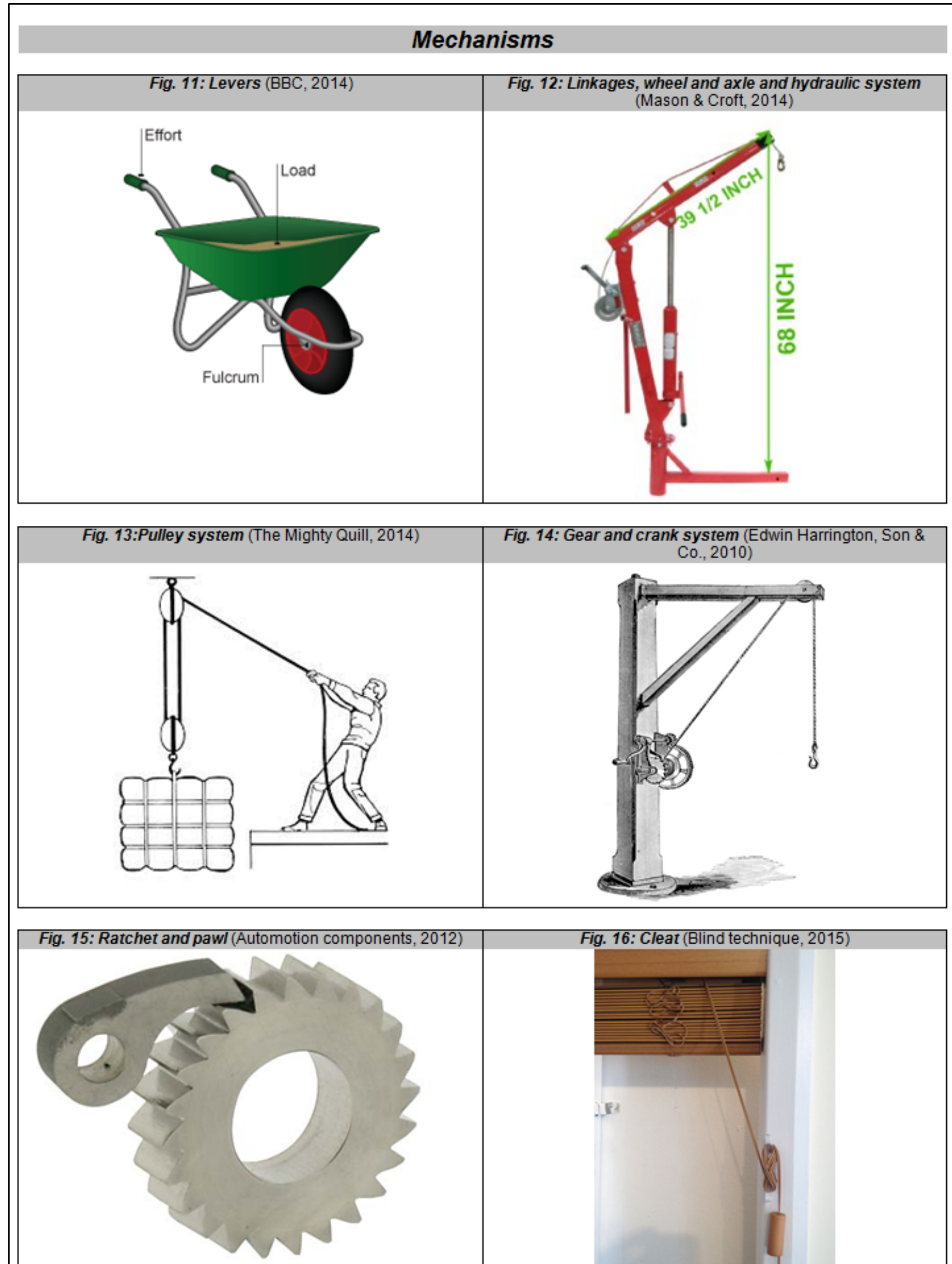


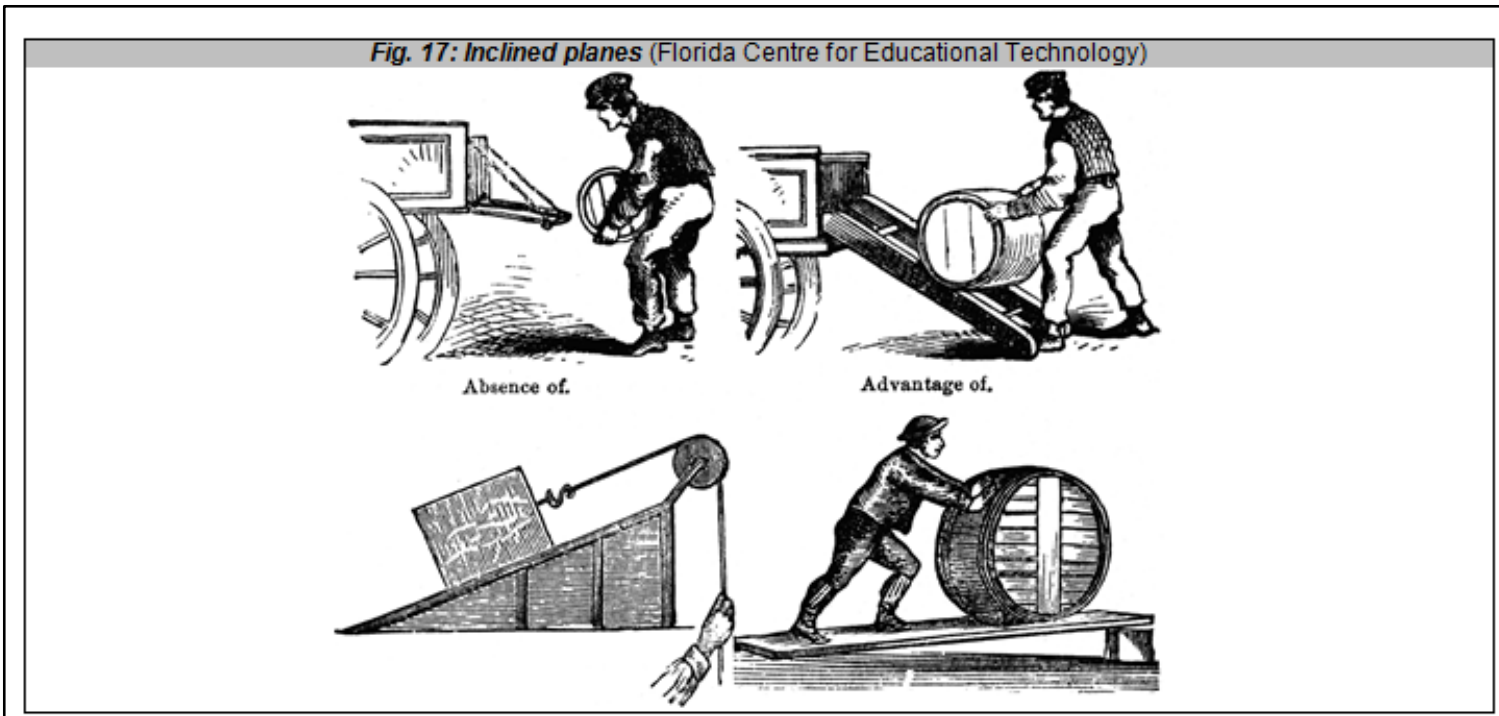

\section{Existing solutions}

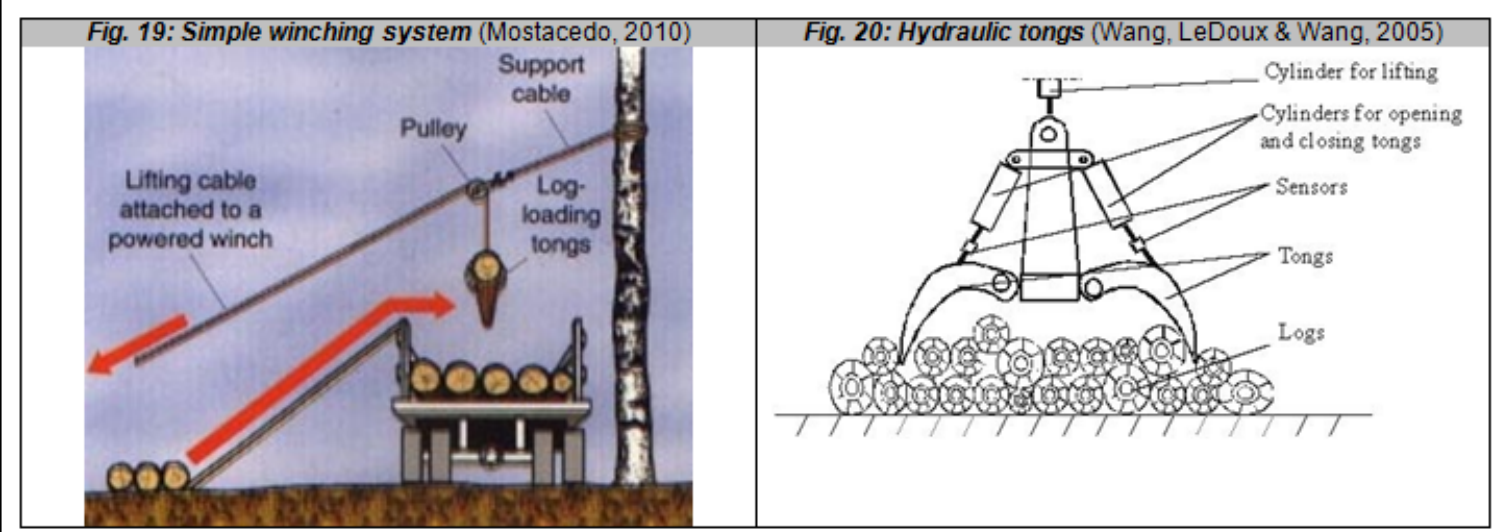



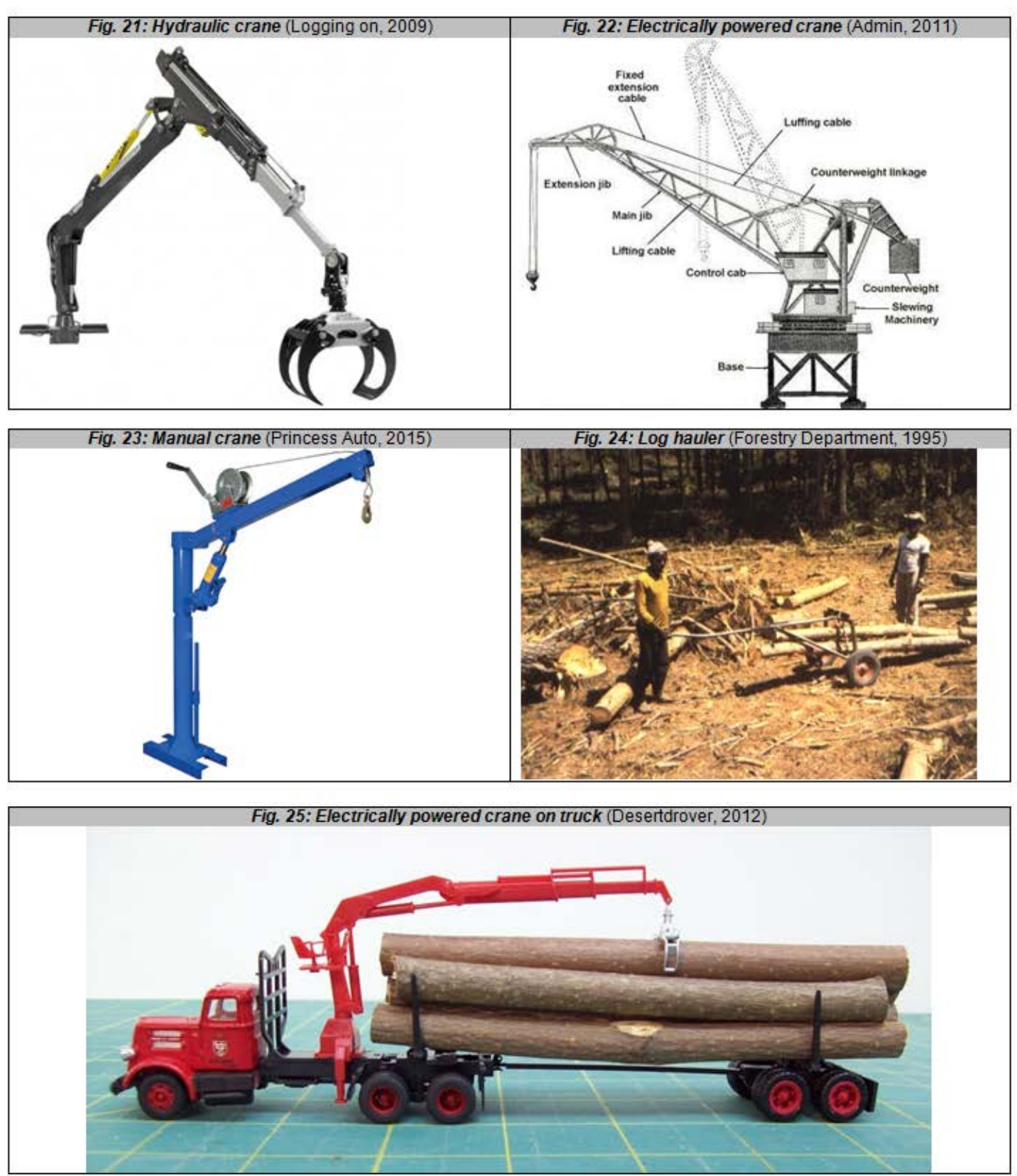

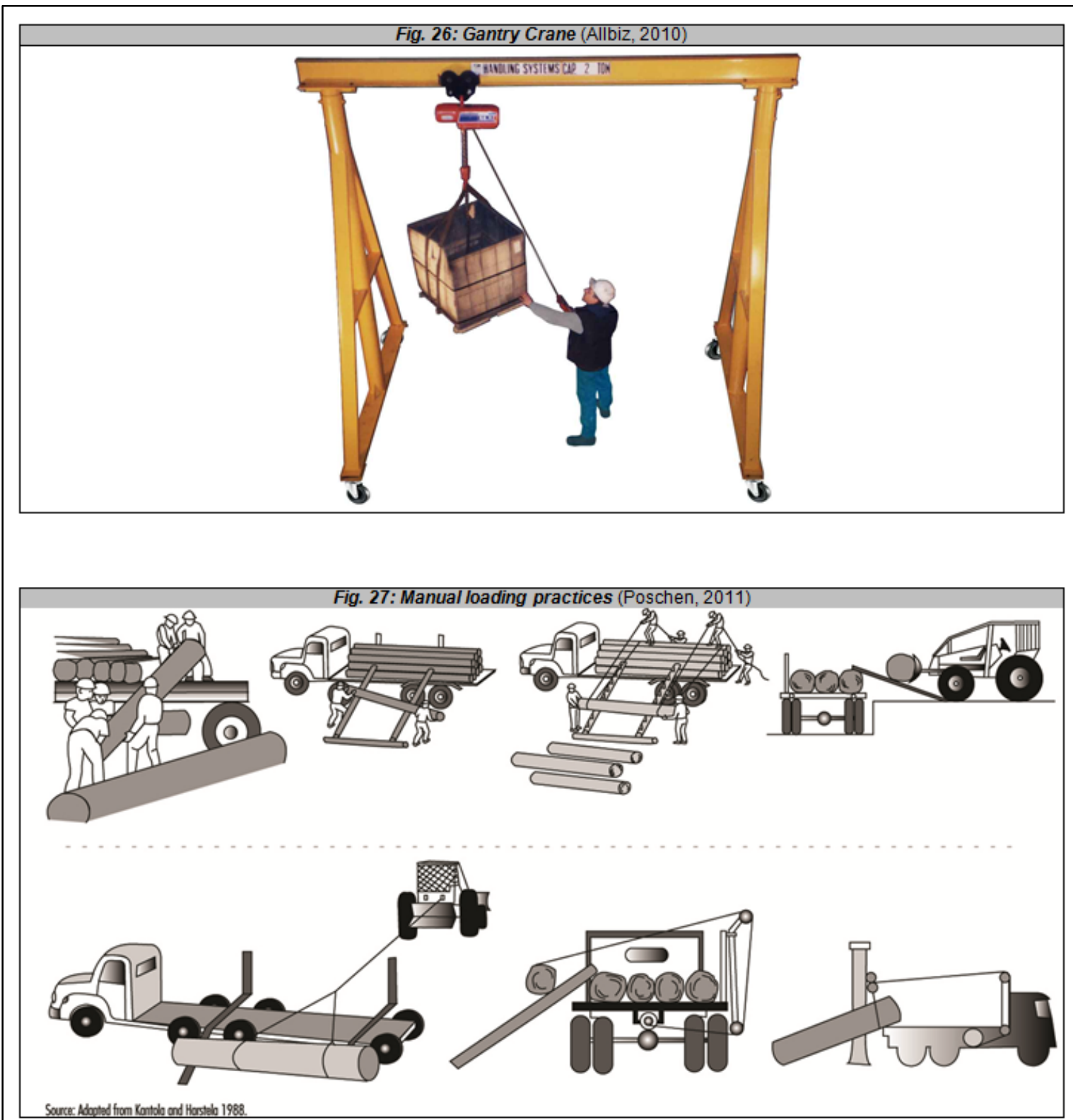

http://www.ejmste.com 